\title{
Acadêmicos na berlinda ou como cada um escreve a História?: uma reflexão sobre o embate entre historiadores acadêmicos e não acadêmicos no Brasil à luz dos debates sobre Public History*
}

\author{
Scholars on the hot seat, or 'how does each one write History?': the clash \\ between academic and non-academic historians in Brazil in the light of \\ the debates on Public History
}

\author{
Jurandir Malerba \\ jurandir.malerba@pucrs.br \\ Pontifícia Universidade Católica do Rio Grande do Sul \\ Professor permanente \\ Av. Ipiranga, 6681, Prédio 3, Sala 303 \\ 90619-900 - Porto Alegre - RS \\ Brasil
}

\begin{abstract}
Resumo
Indicadores diversos sugerem uma crescente demanda por história pelo público leigo nos últimos anos, demanda que vem sendo suprida por profissionais não treinados na academia. Os objetivos deste texto são os de pensar o próprio conceito de história pública e sua aplicabilidade no Brasil, assim como analisar três autores leigos que se tornaram best-sellers como escritores de história no Brasil. Nosso argumento é o de que a difusão massiva dessas obras tem implicações de ordem técnica e ética diante das quais cabe aos historiadores treinados no sistema de pós-graduação se manifestar.
\end{abstract}

Palavras-chave

Historiografia brasileira; História pública; Teoria da história.

\begin{abstract}
Different indicators suggest an increasing demand for history by the lay audience in the recent years, a demand that has been supplied by authors without formal academic training. The objectives of this paper are to think the concept of public history and its applicability in Brazil, and to analyze the contributions of three lay authors who have become best sellers as writers of history in Brazil. Our argument is that the mass dissemination of these works has implications both from a technical and ethical standpoint, and that it is a task of university-trained historians to have a position in regard to them.
\end{abstract}

\section{Keywords}

Brazilian Historiography; Public history; Theory of history.

Recebido em: 12/9/2013

Aprovado em: 18/11/2013

\footnotetext{
* Texto modificado da comunicação originalmente apresentada no congresso The Future of The Theory and Philosophy of History, ocorrido na cidade de Gante, Bélgica, entre os dias 10 e 12 de julho de 2013. Pela generosidade das leituras em primeira mão, minha gratidão aos colegas Carlos Fico, Pedro Caldas e Sérgio Ricardo da Mata. Agradeço ainda a Bruno Leal, Daniel Becker e Eduardo Kafer pelo apoio na coleta de dados, assim como a contribuição profissional dos consultores ad hoc que avaliaram este texto para a presente publicação em História da Historiografia. Esta pesquisa foi desenvolvida com bolsa Produtividade do CNPq.
} 
É bastante sintomático que a discussão acadêmica sobre Public History não tenha jamais sido desenvolvida no Brasil, como foi em outros países, não obstante muitos profissionais brasileiros confrontarem-se diariamente com as questões próprias desse fluido subcampo - tenham ou não consciência disso seus praticantes. Nestes dias de turbulentos debates e nos que tramita em regime de urgência no Congresso Nacional o PL 4.699/2012, do senador Paulo Paim (PT), que trata da profissionalização do historiador, com nervosas vozes em contra e a favor, a discussão teoricamente orientada sobre o que fazem e quem são os historiadores que ocupam a esfera pública faz-se, mais que apropriada, urgente (Cf. MOTTA 2013; MARSHALL 2013; GRINBERG 2013). ${ }^{1}$

Embora a prática seja muito anterior, muitos autores já mostraram como o conceito de "história pública" surgiu com a grande crise de empregos da década de 1970 nos Estados Unidos, quando o historiador Robert Kelley, entre outros, procurou conceituar esse fenômeno do surgimento (ou da criação!) de carreiras ou de um potencial mercado de trabalho alternativos à carreira acadêmica para historiadores que não conseguiam ingressar nos postos das universidades. Assim, "Public History," definiu Kelley, "refere-se ao emprego de historiadores e do método histórico fora da academia" (KELLEY 1978 apud DAVISON 1991; HOLL 2008, p. 30 e ss.). ${ }^{2}$ Ao longo de quatro décadas, a expressão Public History veio se constituindo num campo marcadamente abrangente, difuso e mutante, inclusive com acepções diferentes conforme sua prática nacional, como veremos a seguir. Como observaram Jill Liddington e Simon Ditchfield:

O uso consciente do termo "história pública" cresceu de maneiras distintas - em lugares, momentos e de maneiras diferentes. Ela varia entre os países relativamente "novos" que se reinventam como repúblicas (e. g. Estados Unidos) ou que se definem como distintos do seu passado colonial (por exemplo, Austrália); "velhas" nações (por exemplo, a Grã-Bretanha), que podem eventualmente se sentir mais confortáveis com a palavra "herança"; e entre, digamos, as nações de língua francesa ou italiana, que usam uma terminologia diferente (por exemplo, patrimoine na França e patrimonio na Itália, sendo que ambos termos têm conotações nacionais muito particulares) (LIDDINGTON; DITCHFIELD 2005, p. 40, tradução nossa).

Em outro trabalho anterior, Liddington já se perguntava sobre o que seria, afinal, a tal Public History e sobre o que fazem os Public Historians (LIDDINGTON 2002, p. 83-93). ${ }^{3}$ O fenômeno é sensível em todo lugar. Na Europa e nos Estados Unidos (assim como na Austrália), por exemplo, ganharam picos de audiência programas de televisão como as séries $A$ history of Britain, de Simon Schamma (exibida na $\mathrm{BBC}$ ), ou o documentário dramatizado $A$ Band of Brothers, de Steven

\footnotetext{
${ }^{1}$ Só muito recentemente historiadores brasileiros voltaram-se ao conceito, como se ilustra com a inserção de um simpósio temático sobre Conhecimento Histórico e Diálogo Social no Simpósio Nacional de História da ANPUH em Natal, em julho de 2013. A bibliografia em língua portuguesa é exígua. Cf. ALMEIDA; ROVAI 2011. 2 Os historiadores estão até hoje discutindo sobre o significado da expressão Public History. Ver: H-PUBLIC; "Public History, Public Historians, and the American Historical Association Report of the Task Force on Public History Submitted to the Council of the Association", December 2003. Disponível em: www.historians.org/ governance/tfph/TFPHreport.htm.

${ }^{3}$ É tão notável o estranhamento desses conceitos no Brasil que chega a se refletir nas traduções, que muito deixam a desejar: "história pública" ou "historiadores públicos".
} 
Spielberg, que foi veiculado na TV aberta no Brasil; ou, ainda, as discussões em programas de todo tipo de mídia (internet, TV, rádio) sobre memória, lembrança, trauma, luto e esquecimento (em países com experiências devastadoras da Segunda Guerra, como a Alemanha, o Japão, a Inglaterra e os Estados Unidos, ou que passaram por regimes políticos de exceção, como a Argentina, o Chile e o Brasil). ${ }^{4}$ O entusiasmo pela história viva ${ }^{5}$ contagia as nações. No Brasil, onde os folhetins televisivos têm grande audiência, incontáveis minisséries de sucesso tiveram como enredo questões de fundo histórico. Seguindo a moda estrangeira, inúmeras revistas de história com fim de divulgação científica circulam hoje no país. ${ }^{6}$ Em suas mais diversas formas de apresentação popular, também aqui o passado nos cerca. Editores, publicitários e homens de mídia em geral descobriram que o passado pode representar bons negócios. Uma ampla demanda social por história é patente, e historiadores rompem a "torre de marfim" para tornarem-se personas públicas. Mas, afinal, como hoje se define essa tal de Public History? Sem qualquer pretensão de "esgotar" a discussão, mas com o intuito deliberado de mapear o debate, muito pouco ou quase nada explorado em nossa língua, podemos generalizar reconhecendo a existência de diferentes acepções do termo, que geram práticas diversas conforme distintas tradições historiográficas nacionais.

Robert Kelley apontava que "historiadores públicos entram em ação sempre que, em suas especialidades, tomam parte no processo público" (KELLEY 1978). Desde então, e rapidamente, a Public History tornou-se um campo de aberta polêmica nos Estados Unidos da América. A geração de radicais do Vietnã contestou as pretensões da velha elite branca de uso e posse exclusivos do passado; e criticou as nostálgicas "vilas museus" fundadas pelo capital privado7 por distorcerem o passado, mistificarem o modo como o presente se constituiu e, desse modo, contribuírem para inibir a ação política na construção do futuro (WALLACE 1986, p. 146).

Desde o final dos anos 1990, nos Estados Unidos, a Public History encontra-se institucionalizada dentro das universidades. Em 1996, o National Council on Public History (NCPH) já arrolava mais de cinquenta programas de pós- graduação (graduate studies, nosso Stricto Sensu) voltados, em geral, para cursos principais em História e Administração Pública com habilitações em áreas como História Oral, Administração de Arquivos, Planejamento Urbano e História Ambiental. As universidades católicas estão na ponta do processo. A Howard University, em Washington D.C., sustenta a Association for the Study of Afro-

\footnotetext{
${ }^{4}$ Cf. o estimulante livro de Bevernage (2012), que se serve dos casos da Argentina, África do Sul e Serra Leoa para refletir sobre o passado que não passa, a desconstrução do tempo e a história e o trabalho de luto. ${ }^{5}$ A Ediouro mantém uma importante revista com esse título: História viva: a história que está acontecendo agora. Disponível em: http://www.ediouro.com.br/site/magazines/content_magazine/5. Acesso em: 20 maio 2014.

${ }^{6}$ Em 2003, o jornal Estado de São Paulo anunciava o início das atividades da revista Nossa História, então a mais importante do país, com tiragem inicial de 50 mil exemplares. Disponível em: http://www.estadao. com.br/arquivo/arteelazer/2003/not20031022p509.htm. Acesso em: 20 maio 2014. Do fim da parceria da Fundação Biblioteca Nacional (FBNRJ) e Editora Vera Cruz surgiu a Revista de História da Biblioteca Nacional. Cf. RIBEIRO; AMOROSO 2010.

7 Como o Rockefeller's colonial Williamsburg (um imenso parque temático na Virginia que possui até um spa, bancado pela Fundação John D. Rockefeller Jr) ou a Henry Ford's Greenfield Village, financiada pela fundação homônima, em Dearborn, Michigan. Não temos nada parecido no Brasil com essa envergadura comercial.
} 
-American Life and History; já a Middle Tennessee State University, próxima a Nashville, mantém tanto a Country Music Foundation como a famosa Graceland, em Memphis. Entre os postos de trabalho conquistados por estudantes formados destacam-se o gigante National Park Service (NPS) e a Smithsonian Institution, a US Senate Historical Office, assim como o Wells Fargo Bank, o Gene Autry Museum e o Lower East Side Tenement Museum, em New York (NCPH 1996; RITCHIE 2001). ${ }^{8}$ Num país como o nosso, em que o Ministro da Educação pergunta "o que museu tem a ver com Educação?", torna-se até difícil conduzir essa discussão (KAZ 2013).

Na Austrália, informa-nos ainda Jill Liddington, a história abriu-se ao mercado como em nenhum outro lugar. O jornal acadêmico Australian Historical Studies anuncia com entusiasmo que os historiadores freelance atuam como verdadeiros microempresários; e os negócios crescem vertiginosamente (LIDDINGTON 2002, p. 86). Já na Inglaterra, a Public History foi pautada pela discussão sobre "herança" e memória. A disputa da memória pública aconteceu em dois polos: um com forte apelo à tradição (conservador, por assim dizer) e outro popular, grass roots, proposto pelo historiador socialista Raphael Sammuel (LIDDINGTON 2002, p. 87; WRIGHT 1985, p. 53-55; HEWISON 1987, p 31, 55, 111-118). ${ }^{9}$

Ainda na Inglaterra, Ludmilla Jordanova propôs uma perspectiva diferente de prática da Public History, a "história como entretenimento", por meio da qual uma elite profissional - não apenas "treinada" na universidade, mas composta por acadêmicos altamente competentes que debatessem entre si regularmente 30 por meio de suas publicações e conferências - em colaboração com uma ampla rede de companhias midiáticas, editores e museus, deveria ser capaz de alcançar um vasto público leigo (JORDANOVA 2000, p. 6). Em todo caso, ficam patentes: 1. a questão do treinamento profissional para quem quer que pretenda explorar a história e levá-la ao grande público; 2 o imperativo da consideração da questão da audiência na definição do que seja e de como se deve praticar a história pública. Historiadores "públicos" devem estar sempre precavidos de sua audiência e, certamente, sempre desejarão, desde o início de uma ideia ou projeto, alcançar um público cada vez maior de espectadores ou leitores de modo a facultar acesso ao passado ao grande público. O problema, a meu ver, é quando a audiência cada vez maior a qualquer custo se torna um fim em si mesmo (WINTER 1996, p. 169). Procuraremos tratar esses dois temas a seguir.

Um ponto fundamental a se considerar na busca de uma definição categórica de Public History é a questão da formação de seus praticantes. Autores como Jack M. Holl sustentam que as atividades profissionais de "historiadores práticos"10 e "acadêmicos" são eminentemente distintas, não obstante o common ground que compartilham. Para Holl, o que distingue os historiadores práticos não é

\footnotetext{
${ }^{8} \mathrm{O}$ site http://www.publichistory.org inclui resenhas, dicas de empregos, além de oferecer outros serviços. ${ }^{9}$ Liddington resgata a importância da experiência de Sammuel no Ruskin College, uma faculdade para adultos que, a partir de 1996, com Sammuel à frente, ofereceu um MA em tempo parcial em Public History. Seu programa inclui o estudo de memória popular e história visual junto com um grupo de discussão em Public History dedicado a fazer a ponte entre a academia e o "mundo real". Cf. http://www.ruskin.ac.uk/prospectus. Acesso em 27 jul. 2014. Ver também KEAN; MARTIN; MORGAN 2000; SAMMUEL 1994, p. 242, 207, $210,297$. 10 A terminologia para designar os historiadores não treinados na universidade é ampla: historymakers, popular historians, lay historians (escritores de história, historiadores populares, historiadores leigos).
} 
sua bagagem intelectual, adquirida por meio do treinamento (mormente nas universidades) que eles compartilham com os historiadores acadêmicos, mas sim sua cultura de trabalho, que é moldada por identidades, perspectivas, missão e valores distintos. Alguns historiadores têm enfatizado esse terreno comum compartilhado por historiadores "práticos" e acadêmicos. Celebrar esse entendimento de um suposto "terreno comum" entre ambos, no entanto, pode mascarar as diferenças culturais fundamentais entre os historiadores que praticam história no sentido de sua vulgarização e historiadores com formação técnica que, ademais, ensinam (HOLL 2008, p. 30). De qualquer modo, em todos os países mencionados acima, onde se pratica e se discute a "história pública", "popular historymakers" e "professional historians" (bem entendido, historiadores acadêmicos!) passam ambos por uma formação de expertise, um treinamento (universitário) especializado.

Aquela definição de Kelley segundo a qual a diferença primordial entre historiadores práticos e acadêmicos residiria apenas em seu lugar de atuação profissional (um atuaria no circuito fechado da academia, e o outro, nos horizontes abertos pelas diversas mídias) perdurou por muitos anos. Escrevendo ainda em 2001, Donald Ritchie afirmava que tanto historiadores acadêmicos (mesmo atuando como intelectuasi na esfera pública) quanto historiadores públicos nos EUA procuravam atingir grandes audiências, mais amplas que o círculo de seus pares. Enquanto acadêmicos, como intelectuais e cidadãos, podem comentar livremente sobre questões políticas atuais, os "historiadores públicos" tendem a utilizar suas habilidades de forma mais sutil para moldar a consciência pública por meio da apresentação da história em linguagem popular, em museus, sítios históricos, documentários e websites. Ritchie enfatizava, então, dois aspectos importantes: primeiro, mais uma vez, a importância da questão da "audiência" como fator fundamental da Public History. E, por outro lado, a inserção dos historiadores nos grandes debates públicos (RITCHIE 2001, p. 92).

Nesse último quesito, com pouquíssimas exceções, devemos reconhecer que a historiografia acadêmica brasileira ainda tem jogado um papel muito tímido, ao abrir mão da ocupação dos espaços públicos de debate para manter-]se confinada nos circuitos fechados da academia. Ainda segundo Ritchie (2001, p. 93), "[...] historiadores públicos [leigos] geralmente se abstêm de expressar publicamente opiniões pessoais sobre questões políticas. Em vez disso, eles preferem utilizar suas habilidades de forma mais sutil no trabalho de moldar a consciência pública por meio da apresentação do passado em lugares públicos".

O crescimento desse campo sem fronteiras muito definidas que se chamou de Public History articula-se de modo orgânico com a recente explosão ruidosa de formas populares de apresentação do passado. Esses mesmos fenômenos acontecem em maior ou menor medida no Brasil: constata-se uma sensível demanda social por história nos mais diversos espaços de formação de opinião fora das universidades, novos lugares de exercício da profissão, uma demanda crescente de consumo popular de história, verificável no aparecimento de 
revistas especializadas de divulgação com grandes tiragens ${ }^{11} \mathrm{e}$, por outro lado, uma agressiva produção "historiográfica" que insiste em se autopromover como uma "nova história" - não acadêmica, diferente e superior àquela. Tal ampliação gigantesca do interesse pelo campo, levada a cabo por profissionais tanto internos como externos à área acadêmica da história, tem duas implicações incontornáveis. A primeira é que o interesse pelo passado, ou, ao menos, suas formas populares de apresentação, atualmente nos cercam por todos os lados. Hoje o passado significa "negócios" e, não menos importante, "poder"! Um segundo ponto que distingue o Brasil dos outros casos que vimos apresentando é que, lá em outros países onde se pratica e se discute o estatuto da Public History, historiadores acadêmicos, com formação universitária, compartilham o mesmo common ground dos produtores de versões populares da história. ${ }^{12}$ Os historiadores "públicos" no exterior, que conquistaram ou criaram novas áreas de atuação profissional, seja em organismos estatais ou privados, na mídia, em museus e arquivos, em sindicatos e associações de classe, seja nos novos canais virtuais, todos eles têm formação, treinamento universitário profissional no tratamento dos princípios ou fundamentos da história como ciência. Ora, isso não é o que se passa no Brasil, onde a perícia narrativa e as articulações mercadológicas parecem ser suficientes para garantir a qualquer leigo o domínio do ofício.

Neste ensaio, meu objetivo é o de pensar a prática da história não acadêmica no Brasil à luz de algumas dessas questões suscitadas pelos 32 debates da Public/Popular History. Qual o perfil e que tipo de história esses historiadores práticos produzem? Quais as implicações de uma historiografia orientada pelos negócios ou pelo mercado?

Conforme já observaram alguns autores importantes como Roy Rosenzweig, o lado bom da coisa é que existe uma demanda social enorme por história, ou seja, a história está "bombando" (ROSENZWEIG 2000, p. 35-38). Mas há também um lado sombrio desse fenômeno, que é justamente o da qualidade dessa história feita por pessoas sem treinamento profissional. Um dos maiores especialistas na área, Roy Rosenzweig, é muito crítico. Essa história produzida por leigos costuma ser uma história muito ruim. A história social, processual, interpretativa, estrutural, analítica, crítica, não chega ao grande público, e sim a história paroquial, episódica, factual, pitoresca, anedótica, biográfica, das grandes batalhas, em rápidas narrativas dramáticas inflamadas. Para Rosenzweig, a história é importante para o público. O problema é que essa história popular é de qualidade questionável.

\footnotetext{
${ }^{11}$ Como História viva, Revista de História da Biblioteca Nacional, Aventuras na História, Leituras da história, Desvendando a História, BBC História, História em curso, e outras revistas exclusivamente virtuais: história e-história, disponível em: http://www.historiaehistoria.com.br. Acesso em 14 maio 2014; Histórica - revista online do Arquivo do Estado de São Paulo. Disponível em: http://www.historica.arquivoestado.sp.gov.br/ sobre. Acesso em 27 jul. 2014. As redes sociais têm um papel importante para a divulgação do interesse pela história. O Café História (http://cafehistoria.ning.com) conta com cerca de 50 mil membros, 24 mil amigos no Facebook e 145 mil seguidores no Twitter.

12 "Populares" sem nenhuma conotação pejorativa, mas apenas no sentido de uma história que se projeta a alcançar uma audiência de massa e, portanto, a se popularizar.
} 
São dois tipos de histórias de qualidade duvidosa as produzidas com vistas ao grande público. Parte delas se resume a histórias triviais de família, coleções de objetos pessoais (selos, cartas, diários), biografias ornadas com as lembranças e preconceitos dos mais velhos. E, por outro lado, temos a velha história oitocentista de grandes fatos e personagens, a história évenementielle que tanto combateu Lucien Febvre. Rosenzweig mostra-se preocupado com isso no sentido de que "historiadores não profissionais têm suas próprias preferências, desejos e caprichos, e essas histórias orais pessoais, de grupo ou bairro podem ser demasiado estreitas e paroquiais". A história factual, dos grandes personagens e episódios, foi massivamente criticada desde a virada do século XIX para o XX, para retomarmos 0 assunto aqui. ${ }^{13}$ Contadores de estórias populares, não treinados na reflexão histórica para a formulação de problemas, na pesquisa documental e na análise teorica e metodologicamente embasada, tanto os que enfatizam a experiência pessoal e o depoimento de primeira mão quanto os que constroem narrativas enredadas como sagas, na maioria das vezes subestimam estruturas envolventes maiores ou conjuntos complexos de fatores constituintes de qualquer acontecimento ou processo histórico (GRAHAM, JR. 2000).

Certamente há muitas décadas historiadores leigos vêm tendo uma importante participação pública no Brasil. Os especialistas concordam em que a historiografia brasileira teve início no século XIX, nas arcadas do Instituto Histórico e Geográfico Brasileiro, produzida eminentemente por bacharéis em Direito e diplomatas, enfim, leigos. Ao longo do século $X X$, os maiores historiadores brasileiros, que se tornaram canônicos, como Sérgio Buarque de Holanda, Caio Prado Jr e Raimundo Faoro, eram autodidatas. Mas o nosso foco não é essa história não profissional. Também data do final dos anos 1970 e, sobretudo, dos anos 1980 o movimento de grande difusão editorial que tornou famosos como escritores de história muitos jornalistas como Ruy Castro, Fernando Morais, Zuenir Ventura, Jorge Caldeira e, depois, Elio Gaspari. Eles escreveram uma espécie de "jornalismo de época" de qualidade, na melhor acepção do termo "história popular". Dedicaram-se à escrita de biografias de personagens famosos, apoiando-se em pesquisa bibliográfica e documental rigorosa e numa linguagem saborosa, com enredos de romance. Com o sucesso desse nicho de mercado, passaram a escrever sobre períodos históricos, como os da época da bossa-nova, o Rio de Janeiro da época de D. João VI ou os anos da ditadura militar. Além de boa informação e de uma prosa de alta qualidade, esses livros tinham em comum tiragens enormes, contando-se em dezenas de milhares de exemplares vendidos em poucas semanas depois do lançamento. Como homens de mídia (eles próprios a "cara" da mídia), com nomes reconhecidos e de credibilidade, não Ihes foi difícil usar a seu favor os meios de comunicação onde já atuavam havia

\footnotetext{
${ }_{13}$ Para uma introdução no assunto, ver MALERBA 2013.
} 
décadas. ${ }^{14}$ Seu trabalho pioneiro foi decisivo para a expansão do público leitor de história no Brasil.

A demanda crescente por história do público não especializado é um fato que só os gestores da educação no Brasil não enxergam com propriedade, haja vista o expurgo das disciplinas de história dos curricula do ensino fundamental e médio em favor das matemáticas e da língua portuguesa. Como índice dessa explosão de demanda pública por história poderíamos indicar o surgimento de inúmeras revistas de divulgação científica, um número crescente de programas de televisão, entre novelas e minisséries, redes sociais e websites, que têm a história como tema. As revistas de divulgação, em particular, cumprem o papel que as discussões sobre Public History reclamam. Nas palavras de Luciano Figueiredo, historiador acadêmico e antigo editor da mais importante revista de divulgação do Brasil, a Revista de História da Biblioteca Nacional:

História e ciências humanas têm um expressivo papel mobilizador junto aos indivíduos e grupos, uma vez que lidam com identidade, memória, participação e organização públicas, interação e confrontos, assim como condições de existência. São processos que têm uma linha direta com o debate nas universidades e centros de pesquisa e, por isso, difundir o que pensamos ali é alcançar interlocutores até então alheios, reformular conceitos cristalizados por aí, formar novos referenciais de consciência. Logo, cuidar da formação de um público. Desde aqui deve ficar claro o que chamamos de "divulgação científica" para não embaralharmos a discussão proposta por esta entrevista. Trata-se da apresentação de conhecimento acadêmico, acompanhada por especialistas da área, sob novas formas e suportes, para um público ampliado (RIBEIRO; AMOROSO 2010).15

Mas o foco de análise aqui também não são os veículos de divulgação científica, produzidos por profissionais treinados e que cumprem um importante papel de colocar a história crítica, documentada e teoricamente fundamentada ao alcance do grande público, em particular como subsidiária da atividade docente no ensino básico (fundamental e médio). Trata-se de outro fenômeno, que surgiu no vácuo das ruidosas comemorações do quinto centenário da "descoberta" do Brasil. No final dos anos 1990, um jornalista esportivo

\footnotetext{
${ }_{14}$ De Ruy Casto, entre outros sucessos, são Chega de saudade: a história e as histórias da Bossa-Nova (1990); O anjo pornográfico: a vida de Nelson Rodrigues (1992); Estrela solitária. um brasileiro chamado Garrincha (1995); Carmen: uma biografia (2005); Era no tempo do rei: um romance da chegada da corte (2007). De Fernando Morais, Olga (1985); Chatô, o rei do Brasil (1994); Os últimos soldados da Guerra Fria (2011). De Zuenir Ventura, 1968: o ano que não terminou (1995); Chico Mendes: crime e castigo (2003); 1968: o que fizemos de nós (2009). Totalmente fixados no território da história, são de Jorge Caldeira: Noel Rosa, de costas para o mar (1992); Mauá, empresário do Império (1995); Viagem pela História do Brasil (1997); A nação mercantilista: ensaios sobre o Brasil (1999); A construção do samba (2007); Brasil - a história contada por quem viu (2008). Elio Gaspari publicou a polêmica tetralogia sobre os anos da ditadura civil-militar no Brasil: A ditadura envergonhada (2002); A ditadura escancarada (2002); A ditadura derrotada, 2003; e A ditadura encurralada (2004).

${ }^{15}$ No momento em que reviso este texto para publicação, chega-me às mãos um volume, História do Brasil para ocupados, organizado por Luciano Figueiredo, em que o editor reuniu cerca de oitenta pequenos textos, muitos veiculados pelas revistas de divulgação como a Revista de História da Biblioteca Nacional, de que foi editor por anos. Em seis grandes capítulos (Pátria, Fé, Poder, Povo, Guerra e Construtores), o editor apresenta uma proposta inovadora de escritura histórica para o grande público, numa história do Brasil "arranjada como um caleidoscópio". O diferencial dessa obra é o de que, nessa estrutura narrativa que foge ao ordenamento cronológico e à utilização do pesado arcabouço teórico em que se amparam os historiadores, oferece-se uma leitura prazerosa e ao mesmo tempo arejada que traz a público (e ao grande público) as mais recentes aquisições científicas produzidas na academia. Já não é mais possível repetir o mantra de que os historiadores acadêmicos são chatos ou não sabem escrever. Cf. FIGUEIREDO 2013.
} 
gaúcho, com boa experiência editorial, percebeu que havia um potencial nicho de mercado para a história no país. Para aproveitar a onda mercadológica das efemérides, Eduardo Bueno apresentou a uma grande editora o projeto de uma coleção, Terra Brasilis, composta inicialmente por três obras: A viagem do Descobrimento: a verdadeira história da expedição de Cabral (1998); Náufragos, traficantes e degredados: as primeiras expedições ao Brasil (1998); e Capitães do Brasil: a verdadeira história da expedição de Cabral (1999). Em 2006, por coincidência ou não do auge dos escândalos políticos do governo federal no Brasil ("Mensalão"), apareceu o quarto volume, A coroa, a cruz e a espada: lei, ordem e corrupção no Brasil Colônia, 1548-1558. Esses livros superam o patamar de milhão de cópias vendidas. Seu autor virou uma espécie de celebridade e passou a dar consultoria e apresentar programas na maior rede privada de televisão do país, a Rede Globo.

Essas obras já foram amiúde resenhadas pela crítica acadêmica, que nelas destacou a fórmula de seu sucesso. O autor apresenta a história do país numa prazerosa narrativa na forma de saga, na qual o destaque recai em personagens excêntricos envolvidos em grandes aventuras, quase no estilo "capa e espada". Porém, no caso desses livros dedicados ao descobrimento e à colonização do Brasil, por exemplo, descura-se a abordagem de processos mais amplos, da perspectiva global, da formação do capitalismo comercial, do contexto europeu, da sociedade estamental portuguesa, do caráter do Estado português e da posição do Portugal da Contrarreforma entre as potências europeias no início da Era Moderna. Assim, nessas obras, do ponto de vista teórico, a base de explicação do devir histórico é carlyleana: é a ação de pessoas iluminadas, verdadeiros heróis, que move a história (MALERBA 2010, p. 191-211); ou a ação de vilões, homens sem caráter, mulheres sem moral. Juízos de valor e supostas características psicológicas como fidelidade, impetuosidade, coragem, imaturidade, futilidade, imoralidade estão na base das ações desses personagens. Politicamente, a obra de Bueno é muito conservadora, pois sua narrativa linear não comporta crítica nem análise; por outro lado, sua perspectiva compartilha com a historiografia do século XIX o fato de ser marcadamente eurocêntrica, como quando discute a exploração dos índios ou a mão de obra escrava. Já se apontou também a grande dívida que o autor tem para com a historiografia acadêmica, nem sempre devidamente creditada. ${ }^{16}$ Talvez até por estratégia de marketing, Bueno adora dizer que escreve diferente e melhor que os historiadores acadêmicos e já protagonizou diversos embates diretos contra eles. ${ }^{17}$ Bueno faz questão de referir-se desdenhosamente aos

\footnotetext{
${ }_{16}$ O uso que o autor faz, por exemplo, da obra de Carlos Malheiros Dias, História da colonização portuguesa do Brasil (Porto, 1921), é, para usar de um eufemismo, muito problemática para os parâmetros da ética acadêmica. Cf. AVELINO 2000, p. 333-337. Veja-se também Maia 2010.

${ }_{17} \mathrm{Na}$ reportagem apresentada por Catarina Wrede é retratada parte da polêmica entre historiadores e Eduardo Bueno a partir de seu quadro "É Muita História", que foi apresentado no programa dominical Fantástico, da Rede Globo, durante alguns meses de 2008. Apresentado pelo jornalista e escritor Eduardo Bueno e pelo jornalista Pedro Bial, o quadro teria "o intuito de aproximar a história do Brasil do povo e torná-la interessante aos seus olhos". Mas o resultado foi bastante polêmico entre professores e historiadores. A Associação Nacional de Professores Universitários de História (Anpuh) manifestou-se à época. Manoel Salgado Guimarães, então presidente da Associação, focou sua crítica no tom do programa. "A forma como a história é transmitida no programa é que nos irrita na Anpuh. O tom é sempre de galhofa. Parece, pelo quadro, que fazer história é uma pilhéria. Por que só conseguimos lidar com o nosso passado dessa maneira? Por que não uma abordagem séria dos fatos, com múltiplas visões que ampliem os horizontes do público? O programa se prende a um
} 
historiadores acadêmicos, a quem chama de historiadores oficiais ou de "facções mumificadas da classe acadêmica". E se pergunta: "Será que os historiadores brasileiros não se envergonham perante o que o Eduardo Bueno e o Jorge Caldeira fizeram? Porque toda minha obra é fruto da vergonha que eu sentia por conhecer tão pouco da história do meu país" (NUNES 2010; BONALDO 2010, p. 13-134). Essa avaliação negativa da historiografia acadêmica, contudo, não se pode explicar senão por algum ardil ou estratégia de marketing, já que o próprio Bueno não faz pesquisa documental e escreve história ancorado, basicamente, na historiografia corrente e em cronistas de época. Por outro lado, a avaliação da qualidade da historiografia acadêmica brasileira por profissionais de outros países é bem diferente da dele. Em recente avaliação, o premiado historiador Marshall Eakin, ex-diretor da Brazilian Studies Association, faz uma avaliação e um prognóstico bem distintos da historiografia brasileira:

Desde os anos 1980, a historiografia brasileira tem atingido uma fase de maturidade, dinamismo e qualidade que é impressionante [...]. Conforme as universidades e a comunidade de historiadores continuarem a crescer nas próximas décadas, o Brasil, sem dúvida, continuará não só a produzir historiografia de alta qualidade sobre a história nacional, mas também irá expandir o alcance e a qualidade do trabalho sobre outras áreas do mundo (EAKIN 2011, passim, tradução nossa).

Essa fúria contra a historiografia acadêmica e gana mercadológica pela história não são prerrogativas da história popular tupiniquim. Em recente resenha de um conjunto de obras, o etno-historiador e professor da University of Missouri-St. Louis, Frederick Fausz, faz um diagnóstico certeiro do fenômeno da entrada da indústria do entretenimento nos canteiros de Clio:

Nesta "era Harry Potter", a rentabilidade dos livros que entretêm supera em muito a qualidade dos livros que educam, com base na profecia autorrealizável de uma indústria editorial guiada pela oferta, indústria essa determinada a demonstrar que há pouca demanda do público por estudos sérios. Essa mentalidade de mercado de massa atinge o seu pico durante grandes aniversários, quando o impacto intelectual de livros produzidos por especialistas acadêmicos é superado pelo apelo comercial de livros escritos por jornalistas. Sobrecapas encantadoras alardeando um livro de importância exagerada muitas vezes disfarçam a decepção de títulos errados, simplesmente se acrescentando "A verdadeira estória" (FAUSZ 2007, p. 576-581).

"A formação de leitores começa por Harry Potter", afirma Laurentino Gomes (PERES 2010), outro conhecido jornalista que, com suporte midiático e visão estratégica e aproveitando-se da efeméride dos 200 anos da transferência da corte para o Brasil (1808-2008), emplacou uma obra que se tornou best-seller em poucos meses e que, durante anos, tem ficado entre os mais vendidos livros de não ficção. 1808 é o título do livro, cujo subtítulo é "Como uma

tipo de divulgação que a historiografia já rompeu há muito tempo", dizia então Manoel Salgado Guimarães. Cf. WREDE 2008. Cf. as críticas do historiador Julio Bentivoglio ao programa comandado por Bueno na Rede Globo (BENTIVOGLIO 2012). 
rainha louca, um príncipe medroso e uma corte corrupta enganaram Napoleão e mudaram a História de Portugal e do Brasil" (GOMES 2007). Em comum com Bueno, a abordagem episódica, a linguagem coloquial, romanesca, e o sucesso de vendas. ${ }^{18}$ A fórmula é a mesma: história no formato de saga; nas veladas explicações históricas, ênfase na psicologia dos personagens, que são condenados ou absolvidos como heróis ou parvos de mau-caráter. O sucesso de sua primeira obra foi tão instantâneo e estrondoso que o autor logo emplacou outro best-seller, 1822, que se refere ao ano da Independência do Brasil. Publicado em 2010, o livro já atingiu as centenas de milhares de exemplares vendidos. Seu título completo é 1822: como um homem sábio, uma princesa triste e um escocês louco por dinheiro ajudaram D. Pedro a criar o Brasil, um país que tinha tudo para dar errado (GOMES 2010). Embora alguns autores provenientes da academia, movidos, talvez, pelo interesse de entrarem ou manterem-se nesse nicho, tenham recebido bem a obra de Gomes (FRANÇA 2007; DEL PRIORE 2007, p. 126-128), ${ }^{19}$ sob a perspectiva da história crítica, suas fragilidades são gritantes.

Dedicado a "professores de História no seu trabalho anônimo de explicar as raízes de um país sem memória", (GOMES 2010) o livro 1822, por sua vez, esmera-se para divulgar a mais simplista e conservadora interpretação sobre o complexo processo que levou à emancipação política do Brasil frente a Portugal. Mais uma vez, desconsidera-se o imperativo e a dinâmica das forças históricas em ação, desde a estrutura de poder do Antigo Regime português, que se dissolvia ante o indomável movimento liberal que assolava a Europa da época napoleônica, ou a tensão entre as potências europeias pelo domínio do Atlântico, até a posição do Brasil no sistema global de trocas comerciais, o papel das famílias e fortunas geradas do/no tráfico negreiro, a estrutura social clivada pela escravidão no Brasil, a participação de camadas populares (libertos e homens pobres em geral), as ideologias e projetos de futuro em contenda, a batalha pela opinião pública por meio da imprensa, o papel das sociedades secretas, ou o peso das guerras de independência nos emergentes vizinhos do antigo sistema colonial espanhol que também se dissolvia. ${ }^{20}$ Restam só os grandes homens, os grandes atores, senhores onipotentes dos desígnios da história. E, mais, abandonando completamente qualquer tentativa de enfeixar quaisquer conjuntos de elementos para a explicação do "1822", o autor assume a ideia mais simplória de que independência não deve ser explicada, mas sim servir de fator explicativo. A independência teria sido apenas um produto da sorte, do acaso - um improviso, por assim dizer. É da ação voluntariosa de homens oniscientes - uma princesa austríaca, um militar mercenário inglês, um príncipe epilético, os deputados das Cortes em Lisboa e um "homem sábio", José Bonifácio - que partem as ações cruciais que levariam à independência. E,

\footnotetext{
${ }^{18}$ Estima-se que 1808 já tenha vendido mais de dois milhões de exemplares, em várias edições e reimpressões. Em 2008, 1808 recebeu o prêmio de melhor Livro de Ensaio da Academia Brasileira de Letras e o Prêmio Jabuti de Literatura na categoria de livro reportagem e de livro do ano de não ficção.

${ }^{19}$ Sobre o fenômeno editorial, ver COLOMBO 2008.

${ }^{20}$ Para duas obras coletivas que reúnem a bibliografia básica sobre esses temas, ver JANCSÓ 2005 e MALERBA 2006.
} 
dado importante, essas decisões só poderiam ser tomadas por estrangeiros e portugueses, jamais por brasileiros.

Não isento de erros factuais básicos - o que não deixa de ser uma ironia -, o livro, como propõe o autor, pretende ser um "mosaico" de personagens e episódios. A narrativa, que talvez tenha na biografia de Dom Pedro seu fio condutor, embaralha-se na sequência voluptuosa de acontecimentos distintos, dos grandes episódios consolidados pela historiografia monarquista tradicional do século XIX e até de segredos de alcova que não se engatam a qualquer lógica explicativa consequente. Do ponto de vista da formação crítica do potencial leitor, o livro chega a ser pernicioso, ao sugerir que são os grandes embusteiros os que fazem a história, que, desde seus primórdios como entidade política autônoma até os dias de hoje, o Brasil é incapaz de se autogovernar e que a construção da nação brasileira é um projeto malogrado (OLIVEIRA 2010, p. 92). A tirar pela sedução das grandes tiragens de 1808 e 1822, não surpreenderá assistirmos na sequência outras a "continuações": 1889, ${ }^{21}$ 1930, 1932 (especial para paulistas), 1964, 1992, 2003...

Radicalizando e potencializando as características da escrita histórica feita por historiadores leigos no Brasil, em 2009 apareceu um livro que logo entrou para a lista de best-sellers, alcançando a marca de mais de 100 mil exemplares vendidos em poucas semanas. Trata-se do Guia politicamente incorreto da história do Brasil, de Leandro Narloch (2009). Do ponto de vista da produção da escrita histórica, o texto se apoia na historiografia disponível, ora para corroborar seus argumentos, ora para detratá-la quando dela discorda. Sob a bandeira do "politicamente correto", mal se disfarça uma visão altamente conservadora, quando não reacionária, retrógrada, eurocêntrica e preconceituosa da/sobre a história do Brasil. Por exemplo, em relação a negros e índios, Narloch reproduz uma interpretação típica das classes senhoriais brasileiras do século XIX segundo a qual a construção do Brasil foi obra de europeus (portugueses) e o Brasil fez-se quase que apesar da existência de negros e índios. ${ }^{22}$ Segundo essa interpretação, baseada numa filosofia iluminista e hegeliana da história, de acordo com a qual a civilização europeia estaria na ponta de um processo civilizatório único, teleológico e universal rumo à perfectibilidade humana - e, portanto, aos europeus caberia levar as luzes de sua civilização aos povos mais atrasados -, a melhor coisa que aconteceu com os índios brasileiros e com os negros trazidos de África foi seu encontro com os portugueses, seus verdadeiros libertadores. Não vou rebater essas inverdades, replicando com historiografia, pois não é disso que se trata, mas aguça a curiosidade intelectual pensar na razão do aparecimento de "leituras" tão francamente conservadoras numa época como a que vivemos, quando se discute socialmente e se aplicam no Estado diferentes políticas de inclusão racial e social.

\footnotetext{
${ }^{21}$ No momento em que reviso este texto tenho notícia de que acaba de sair o novo livro de Laurentino Gomes (GOMES 2013).

${ }^{22}$ Essa visão foi difundida por Francisco Adolfo de Varnhagen, considerado o fundador da historiografia brasileira. Cf. ABREU 1976. Autores importantes dedicaram-se ao estudo da obra e da vida do Visconde de Porto Seguro. Cf. WEHLING 1999, p. 195-220; RODRIGUES 1982, p. 191-225; REIS 1999, p. 23-50; IGLESIAS 2000; ODALIA 1997.
} 
Narloch também faz generalizações superficiais e preconceituosas sobre o que identifica como "alma" dos países. Nesse sentido, o Brasil seria um país "bipolar" em crise com sua identidade:

Haveria aquele país que mal notaria a existência dos outros, como a França, talvez os Estados Unidos. A Alemanha se seguraria calada, sofrendo de culpa, desconfortável consigo e com os colegas ao redor. Uma quarentona insone, em crise por não ser tão rica e atraente quanto no passado, representaria muito bem a Argentina. Claro que haveria também países menos problemáticos, como o Chile ou a Suíça, contentes com a sua pouca relevância. Não seria o caso do Brasil, paciente que sofreria de diversos males psicológicos. Bipolar, oscilaria entre considerações muito negativas e muito positivas sobre si próprio. [E conclui:] a identidade nacional foi sempre um problema psicanalítico no Brasil (NARLOCH 2009, p. 94).

Só alguém muito ignorante da história do Chile poderia fazer tal afirmação. Desde os anos 1830, Santiago tornou-se o centro do pensamento na América do Sul. Devido ao exílio, uma geração de brilhantes intelectuais argentinos, junto com os próprios chilenos, foi requisitada pela elite governante chilena, num período de grande crescimento econômico e estabilidade política, para uma série de empreendimentos nos campos político e intelectual (como a própria fundação da Universidade do Chile, em 1842). Nessas condições ótimas, aquela geração dedicou-se a produzir, a partir do Chile, obras essenciais nos campos do direito, da literatura, da política e da história. Ao longo dos anos 1830 e 1840, desenvolveu-se uma forte colaboração entre intelectuais chilenos e argentinos, que perdurou por todo século, mesmo após o retorno dos argentinos a seu país natal. O cosmopolitismo da intelectualidade latino-americana já foi registrado por uma legião de notáveis estudiosos (Cf. COLMENARES 1987; MAIGUASHCA 2011; THURNER 2013).

Voltando a Narloch, mais à frente em seu guia, seu preconceito se apresenta ingênua e cruamente: "Existem muitos lugares irrelevantes pelo mundo como Porto Rico, a Bélgica, o Paraná - o que não chega a ser um problema" (2009, p. 157). Um dos momentos mais delicados da obra é a referência à ditadura civil-militar que manchou o Brasil entre 1964 e 1985. É cada vez mais comum que novos estudos promovam uma releitura menos ideologizada do período e que cada vez se fale menos em "mocinhos" e "bandidos", como sugere Narloch. Mas o autor toma abertamente um só partido da dicotomia, um partido pró-militar (COLOMBO 2011).

Surfando no sucesso de vendas do guia incorreto da história do Brasil, o autor imediatamente emplacou, em coautoria com outro jornalista (Duda Teixeira), um Guia politicamente incorreto da História da América Latina (NARLOCH; TEIXEIRA 2011), que imediatamente alcançou a top list dos mais vendidos. Nessa continuação, que teve tiragem inicial de 100 mil exemplares, a dupla se propõe a "contar a história que não está nos livros" (NARLOCH; TEIXEIRA 2011). Para tanto, não obstante, os autores pesquisaram mais de cem títulos. A fórmula é a mesma: proposta "didática", capítulos com nomes de personagens icônicos, anedotas e linguagem coloquial, destacando os tópicos 
mais "cabeludos" de cada personagem. Porém, o próprio Narloch não esconde suas intenções com a obra. "O livro foi desenhado para ser um best-seller. Se fosse para não ganhar dinheiro com ele, eu ficaria em casa jogando videogame" (COLOMBO 2011a).

Enfim, o guia incorreto da América Latina reproduz de forma amplificada os preconceitos gerados pela ignorância que separa os brasileiros da América hispânica, considerada como um mundo habitado por caudilhos selvagens onde reinava a anarquia popular. Não vale a pena retomar tanto preconceito. Para quem se propuser a pensar esse tipo de escritura histórica, creio que será mais oportuno focar na forma - de resto, comercialmente muito bem-sucedida - empregada pelo autor, que montou seus guias não como uma narrativa histórica, mas como um mosaico de episódios contados em tom de chiste, de forma pilhérica, picaresca, enfim, de forma anedótica, conceituada como uma narrativa concisa, baseada em uma estrutura dramática de três atos relativos à situação ou exposição, o encontro ou crise e a resolução (que guarda a lição de moral). É para essa forma que quero atentar.

Esse tipo de narrativa daquilo que os franceses chamam faits divers e os ingleses, feature (a propósito, uma expressão corrente no jargão jornalístico para designar os assuntos não categorizáveis nas editoras tradicionais) remete, conceitualmente, a fatos desconectados de historicidade, cujo interesse reside em seu caráter inusitado, pitoresco. Lionel Gossman oferece uma reflexão erudita e profunda da relação entre a história (historiografia) e esse tipo de modalidade narrativa ancorada na anedota. 10 Segundo Gossman, o termo "anedota" (ou "episódio") era e é utilizado para descrever uma ampla gama de narrativas cuja característica definidora essencial é menos sua brevidade (embora a maioria em geral seja bastante curta) do que a sua falta de complexidade. Segundo o Oxford English Dictionary, uma anedota é a "narrativa de um incidente individual, ou de um único evento, narrado como sendo interessante e surpreendente por si só" (GOSSMAN 2003, p. 150 e ss.). Tal definição é muito próxima da conceituação feita por Roland Barthes dos faits divers como uma peça informativa que se esgota em si mesma:

[...] ele contém todo o seu conhecimento dentro de si mesmo: a recepção de um fait divers não requer nenhum conhecimento do mundo, já que ele se refere formalmente a nada além de si mesmo: desastres, assassinatos, sequestros, roubos e excentricidades, tudo se refere a seres humanos, a sua história, a sua condição de alienação, suas fantasias (BARTHES 1966, p. 189 , tradução nossa). ${ }^{23}$

Ele contém as suas circunstâncias, suas causas, seu próprio passado, seus desdobramentos. Enfim, ele não requer nenhuma duração temporal nem contextualização. A anedota, o fait divers, não tem um fim cognitivo, mas moral; não busca conhecer, mas quer pregar.

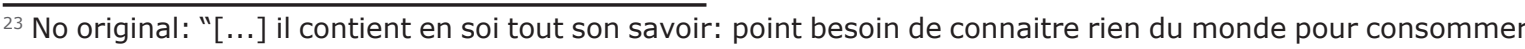
un fait divers; il ne renvoie formellement a rien d'autre qu'a lui-meme; bien sur, son contenu n'est pas étranger au monde: desastres, meurtres, enlevements, agressions, accidents, vols, bizarreries, tout cela renvoie il'homme a son histoire, a son alienation, a ses fantasmes". Ver também ALENCAR s/d.
} 
Além disso, o termo "anedota" foi amplamente utilizado no final do século XVIII e início do século XIX para designar uma espécie de escrita histórica que deliberadamente evitava a "narrativização em larga escala", de acordo com a proposta conceitual de Hayden White. Essas histórias-anedotas parecem se definir por sua recusa ostensiva à sistematização, à totalização e à interpretação e por suas narrações apenas de episódios particulares, isolados, muitas vezes numa ordem cronológica simples, como nos anais e crônicas da Idade Média. Ainda segundo Gossman, o uso mais comum de anedotas por historiadores não parece ter sido especialmente subversivo. As anedotas geralmente funcionaram na escrita histórica não como casos individuais intrigantes ou incomuns a questionarem as noções de ordem histórica, mas como casos particulares exemplificando e confirmando uma regra geral ou tendência ou a servir de epítome a uma situação geral maior (GOSSMAN 2003, p. 155).

Como magistra vitae, a história moderna em seus primórdios era muitas vezes uma coleção de episódios que exemplificavam regras gerais e lições de conduta (CATROGA 2006). Assim, as "histórias" relacionadas na Historische Chronica de J. L. Gottfried, publicada pelo célebre gravador Matthaeus Merian na década de 1620, tinham a intenção de demonstrar que o vício é sempre punido e a virtude, recompensada, da mesma forma que os exemplos nos livros de gramática oferecem ilustrações particulares das regras gerais que regem declinações nominais e conjugações verbais. Como resultado, na Chronica, as narrativas particulares estão relacionadas umas com as outras muito mais em termos das virtudes ou vícios que exemplificam do que em termos de uma conexão histórica interna ou relação entre elas. Apenas a sucessão de datas nas margens estabelece uma frouxa conexão temporal, algo parecido com a conexão que Hayden White considera característica dos anais, distinta das histórias "narrativizadas", e que servem também, ao mesmo tempo, como um sinal de que os eventos narrados não devem ser considerados como fábulas, mas como tendo realmente acontecido (WHITE 1992).

Além disso, se elas deviam funcionar como exemplares, as estórias tinham de ser relativamente curtas, simples e facilmente inteligíveis, em termos de valores tradicionais, em favor de uma compreensão compartilhada dos seres humanos e do mundo. A relação da parte - a narrativa curta individual ou anedota - com o todo (a história) nesse tipo de estória pode ser descrita como alegórica. Cada episódio é um exemplo singular de uma regra geral que exemplifica e ensina valores e virtudes (GOSSMAN 2003, p. 156 e ss.). O que importa nelas não é contar ou explicar a história, mas impor um conjunto de preceitos morais a partir do que se considera (moralmente) certo e errado, ou (politicamente) correto ou incorreto. Narloch, provavelmente sem consciência disso, retoma uma modalidade de escrita histórica antiga, anterior à construção da história como ciência no século XIX, baseada na ecrita rápida, alegórica e normativa, garimpando na historiografia episódios picarescos que corroborem suas posições e ataques conservadores, porém ironicamente travestidos de "politicamente incorretos". 


\section{Conclusões}

O historiador norte-americano Claude Bowers consagrou-se como um dos mais notáveis oradores de sua época. Ainda um estudante secundarista nos anos de 1890, quando a rinha retórica era mais importante que o basquete ou o futebol, ele foi considerado um dos melhores oradores, tendo vencido o Indiana State High School Oratorical Contest com seu discurso "Hamilton, o Construtor". Ao longo da vida, Bowers nutriu uma enorme paixão pela história e pelo grande adversário de Hamilton, Thomas Jefferson, tendo publicado sobre ambos um estudo que se tornou um best-seller. Por volta dos anos 1930, Bowers angariava a reputação de um dos historiadores mais lidos da América (embora jamais tivesse se graduado na área!), no período entre guerras, com o clássico The Tragic Era, que teve a espantosa primeira edição de 100 mil exemplares e doze reedições consecutivas (KNIGHT 1956; SEHLINGER 2000; GARRATY; STERNSTEIN 1996; BANTA 1949; BOWERS 1929).

A história contada por Bowers moldou as mentes e corações dos leitores norte-americanos da época e alicerçou sua ativa militância política, que Ihe garantiu, entre outras coisas, ser o conferencista principal da convenção nacional do Partido Democrático em 1928 (SEHLINGER 2000). Mas há um lado sombrio desse tipo de história popular, dessa história que atinge um grande público. Essa obra clássica de Bowers, até hoje reeditada, foi crucial para tornar massivamente pública uma versão racista da era da Reconstrução americana, que concebia a Guerra de Secessão como uma atrocidade perpetrada contra o Sul inocente pelos "emissários do ódio" nortistas, junto com os incompetentes, egoístas e luxuriosos afro-americanos do Sul. Bowers tinha um propósito partidário claro em seu livro, ao buscar desacreditar o Partido Republicano no Sul do país e consolidar o apoio sulista ao Partido Democrata.

Falando em historia magistra vitae, a parábola por trás da menção a Bowers traz uma "moral da estória" muito séria relativa à complexa questão do historiador com o público, a qual envolve quem está falando, o que se está a dizer, os locais pelos quais a mensagem circula e a relação entre o emissor da mensagem (o escritor, o orador) e o público. Quando se pensa a dimensão pública da história, é preciso considerar não apenas a mensagem ou o locutor, mas como diversas audiências recebem tal mensagem (ROSENZWEIG 2006, p. 859-864; LIDDINGTON 2002, p. 90; JORDANOVA 2000).

Não há dúvidas de que estamos à beira de um campo minado, mas não há como nem por que evitar entrar nele. Diante da impossibilidade de abordar "todos" os tópicos relativos à discussão sobre história pública, meu intuito neste texto foi o de focar um aspecto muito importante, qual seja o da difusão massiva da história popular, construindo minha crítica por meio da análise formal de uma obra dessa historiografia. Nesse sentido, mais que efetivamente propositivo, este ensaio é um convite à discussão, em cuja pauta me parece urgente incluírem-se, entre outros, os seguintes pontos:

1. A escrita da história não é e nem pode ser prerrogativa, propriedade de quem quer que seja, mas há de se manter a crítica permanente do que se 
veicula como historiografia, pois se trata da formação da consciência histórica de homens e mulheres;

2. por conseguinte, é preciso considerar a história popular/pública (que atinge grandes audiências), veiculada por meio de variadas mídias (livros, televisão, internet, cinema, museus), um campo fundamental e permanente de reflexão a exigir a atenção permanente dos historiadores acadêmicos;

3. há, sim, diferenças estruturais entre as formas de apresentação (RÜSEN 2007a) leigas (quer exclusivamente narrativas, quer anedóticas) e as formas de apresentação acadêmicas [complexas, que buscam fazer sentido do passado como história por meio da intelecção e de um conjunto de protocolos intersubjetivamente regulados pela crítica (RÜSEN 2001; 2007b)];

4. para além das questões teóricas e metodológicas, é preciso considerar um componente ético que deve estar presente na constituição das duas práticas historiográficas;

5. é imperiosa a necessidade de os historiadores acadêmicos entrarem nesse debate, inclusive por cuidado para com o ensino e as práticas didáticas;

6. é imperiosa a necessidade de os historiadores acadêmicos assumirem a importância da dimensão pública de sua atividade, ultrapassando os muros da academia para cada vez mais tomar parte, como especialistas, nos debates de interesse público;

7. não há definição de qualidade a priori em qualquer forma de apresentação, pois há trabalhos de ótima e péssima qualidade, historiadores bons e historiadores ruins, independentemente de produzirem história acadêmica ou popular;

8. $\quad$ não se deve lidar com a questão em termos corporativos. Não se trata de uma contenda de "historiadores" versus jornalistas, mas da formação de consciência histórica por meio da disseminação do saber histórico e das instâncias de legitimação desse saber (que, a meu ver, não podem ser ditadas exclusivamente pelas leis do mercado); ${ }^{24}$

9. a crítica competente da historiografia popular produzida por historiadores práticos deve considerar promover o estudo das diferentes linguagens de suas variadas modalidades, por meio das quais se poderão perceber suas diversas estratégias e funções; ${ }^{25}$

10. a compreensão do fenômeno contemporâneo de demanda social por historiografia se beneficiará das abordagens que considerem a inserção da historiografia dentro do campo mais amplo da cultura contemporânea como indústria cultural.

\footnotetext{
${ }^{24}$ Como exemplo da complexidade do quadro, considere-se que há excelentes historiadores sem treinamento universitário que são referências para os historiadores acadêmicos, como Evaldo Cabral de Mello ou Alberto da Costa e Silva, e historiadores com formação acadêmica escrevendo história popular, como Mary del Priori e Marco Antônio Villa, cujo mérito não cabe analisar neste ensaio. Da mesma forma, não se pode avaliar com os mesmos pesos e medidas obras historiográficas de natureza e qualidade tão diversa como as produzidas por jornalistas como Ruy Castro, Fernando Morais, Zuenir Ventura, Jorge Caldeira, Elio Gaspari, Juremir Machado da Silva ou Paulo Markun, por um lado, ou por um Laurentino Gomes, um Eduardo Bueno ou um Narloch, por outro - esses três últimos, aliás, tão diversos entre si. Os dois primeiros são apenas produtores de histórias anódinas, de pouco fôlego analítico, de baixa complexidade; o último, autor de uma história ruim e perniciosa, reacionária. 25 Tendo em mente uma "tópica" das formas da historiografia, conforme propõe RÜSEN 2007b.
} 
Em suma, qualquer um pode escrever história, o que não significa que toda história tenha o mesmo valor e qualidade. Há bons historiadores e historiadores ruins dentro e fora da academia, mas, aqui dentro, faz parte do ofício o processo permanente da metodização racional dos procedimentos e exposição dos argumentos e a crítica (das fontes, dos procedimentos de coleta e sistematização dessas fontes, de problematização temática e perspectivação teórica, de produção textual). Esses mesmos protocolos, esse mesmo padrão de exigência deve ser aplicado a toda historiografia, acadêmica ou não. Se apenas o sucesso de vendas for critério para se avaliar uma obra historiográfica, os parâmetros éticos se esvanecerão e teremos de assistir à disseminação de narrativas históricas de alcance interpretativo pobre, prenhes de anacronismos, erros e preconceitos, como vimos acima.

Alguns autores mais céticos chegaram a levantar que a questão, colocada no debate da pós-modernidade, de se, e em que medida, a história acadêmica ainda é necessária. Assim, para Wulf Kansteiner (1996, p. 215-219), "a preocupação com o futuro da disciplina reflete um problema mais sério". Em sua opinião, ao tratar das representações midiáticas do passado, as polêmicas sobre a historiografia pós-moderna são, em parte, alimentadas por uma consciência crescente da insignificância social e política da produção histórica acadêmica nas sociedades ocidentais contemporâneas. Enfim, segundo o autor, a imensa demanda social por história no mundo atual teria como objeto não a históriaconhecimento, construída por historiadores acadêmicos, mas as narrativas sobre o passado de caráter popular. Essa é mais uma discussão importante, que, no entanto, escapa às possibilidades deste texto, mas que os teóricos e filósofos da história deveriam enfrentar. Passados alguns anos da projeção pessimista de Kansteiner, desejo crer que ela possa ser relativizada. As sociedades contemporâneas precisam da história, tanto da acadêmica quanto da popular. Resta saber se os historiadores acadêmicos terão competência, por um lado, para mostrar à sociedade que fazer sentido do passado como história é importante e necessário; e, por outro, para atender à demanda da grande audiência com a produção de história popular de qualidade.

\section{Referências bibliográficas}

ABREU, Capistrano. Sobre o Visconde de Porto Seguro. In: Ensaios e estudos, $1^{\text {a }}$ série. Rio de Janeiro: Civilização Brasileira, 1976.

ALENCAR, Ana Maria de. O que é o fait divers? Considerações a partir de Roland Barthes. S/D. Disponível em: http://www.letras.ufrj.br/ciencialit/docente/ trabalhos/ana_alencar_fait_divers.html. Acesso em: 15 ago. 2013.

ALMEIDA, Juniele Rabêlo; ROVAI, Marta Gouveia de Oliveira (orgs.). Introdução à História Pública. São Paulo: Letra e Voz, 2011.

AVELINO, Yvone Dias. A grande saga: a viagem cabralina, as primeiras expedições e os primeiros colonizadores. Projeto História, n. 20, p. 333-337, 2000.

BANTA, R. E. (ed.). Indiana Authors and Their Books, 1816-1916. 
Crawfordsville: Wabash College, 1949.

BARTHES, R. Structure du fait divers: essais critiques. Paris: Seuil, 1966.

BENTIVOGLIO, Julio. A independência na TV (postado em 06/12/2012). Disponível em: http://juliobentivoglio.blogspot.com.br/2012/12/a-independenciana-tv.html. Acesso em: 9 abr. 2013.

BEVERNAGE, Berber. History, Memory, and State-sponsored Violence: time and justice. London: Routledge, 2012.

BONAlDO, Rodrigo Bagio. Presentismo e Presentificação do Passado: a Narrativa Jornalística da História na Coleção Terra Brasilis de Eduardo Bueno. Dissertação (Mestrado em História). Programa de Pós-Graduação em História Universidade Federal do Rio Grande do Sul, Porto Alegre, 2010.

BOWERS, Claude. The Tragic Era: the Revolution after Lincoln. Cambridge (MA): The Riverside Press, 1929.

CATROGA, Fernando. Ainda será a História Mestra da Vida? Estudos IberoAmericanos, Edição Especial, n. 2, p. 7-34, 2006.

COLMENARES, Germán. Las convenciones contra la cultura: ensayos sobre la historiografía hispanoamericana del siglo XIX. Bogotá: Tercer Mundo Editores, 1987.

COLOMBO, Lucas. Quatro perguntas para Leandro Narloch, 24 nov. 2011 a. Entrevista concedida a Lucas Colombo. Disponível em http:// minimomultiplo.blogspot.com.br/search/label/Jornalismo. Acesso em: 5 jun. 2013.

COLOMBO, Sylvia. História com "h" minúsculo. Folha de São Paulo. São Paulo, 15 fev. 2011 Disponível em: http://www1.folha.uol.com.br/colunas/ sylviacolombo/875554-historia-com-h-minusculo.shtml. Acesso em: 7 abr. 2013.

. Livro reflete ignorância brasileira sobre América Latina. Folha de São

Paulo. São Paulo, 12 jul. 2014. Disponível em: http://www1.folha.uol. com.br/ilustrada/967286-livro-reflete-ignorancia-brasileira-sobre-aamerica-latina.shtml. Acesso em: 7 abr. 2013. Folha Ilustrada.

- Livro sobre 200 anos da chegada da família real torna-se fenômeno editorial. Folha de São Paulo. São Paulo, 03 mar. 2008. Disponível em: http://www1.folha.uol.com.br/folha/brasil/ult96u378093.shtml. Acesso em: 21 mar. 2013.

DEL PRIORE, Mary. O ano que definiu o Brasil. 1808, do jornalista Laurentino Gomes, lança luz sobre a fuga da família real portuguesa para o Rio fato que mudou o destino nacional. Veja, n. 2025, setembro de 2007. Disponível em: http://veja.abril.com.br/120907/p_126.shtml. Acesso em: 23 mar. 2013.

EAKIN, Marshall. Brazilian Historical Writing. In: WOOLF, Daniel (ed). The 
Oxford History of Historical Writing. Oxford: Oxford University Press, 2011. (V. 5: Historical Writing since 1945).

FAUSZ, Frederick. Jamestown at 400: Caught between a Rock and a Slippery Slope. History News Network Web essay, 5 jul. 2007. Disponível em: http://hnn.us/articles/38375.html.

FIGUEIREDO, Luciano (org.). História do Brasil para ocupados. Rio de Janeiro: Casa da Palavra, 2013.

FRANÇA, Jean Marcel Carvalho. 1808 reconta era joanina com leveza. Folha de São Paulo. São Paulo, 06 out. 2007. Disponível em: http://www1.folha. uol.com.br/fsp/ilustrad/fq0610200721.htm. Acesso em: 7 abr. 2013. Folha Ilustrada.

GARRATY, John Arthur; STERNSTEIN, Jerome L. (eds). Encyclopedia of American Biography. 2a edição. New York: HarperCollins, 1996.

GOMES, Laurentino. 1808: como uma rainha louca, um príncipe medroso e uma corte corrupta enganaram Napoleão e mudaram a História de Portugal e do Brasil. São Paulo: Planeta do Brasil, 2007.

1822: como um homem sábio, uma princesa triste e um escocês louco por dinheiro ajudaram D. Pedro a criar o Brasil, um país que tinha tudo para dar errado. Rio de Janeiro: Nova Fronteira, 2010.

1889: como um Imperador Cansado, um Marechal Vaidoso e um Professor Injustiçado Contribuíram para o Fim da Monarquia e a Proclamação da República no Brasil. São Paulo: Globo, 2013.

GOSSMAN, Lionel. Anecdote and History. History and Theory, v. 42, n. 2, p. 143-168, 2003.

GRAHAM, Jr., Otis L. Dealing Ourselves Back. In: Professional Historians and the Public. The Public Historian, v. 22, n. 1, p. 27-29, 2000.

GRINBERG. Por Um Olhar do Historiador. Ciência Hoje. Disponível em http:// cienciahoje.uol.com.br/colunas/em-tempo/por-um-olhar-do-historiador. Acesso em: 12 ago. 2013

H-PUBLIC. Disponível em https://networks.h-net.org/h-public. Acesso em: 27 jul. 2014.

HOLL, Jack M. Cultures in Conflict: An Argument Against "Common Ground" Between Practicing Professional Historians and Academics. The Public Historian, v. 30, n. 2, p. 29-50, 2008.

IGLÉSIAS, Francisco. Os historiadores do Brasil: capítulos de historiografia brasileira. Rio de Janeiro: Nova Fronteira; Belo Horizonte: UFMG, 2000.

JANCSÓ, István (org.) Independência: História e Historiografia. São Paulo: Editora Hucitec, 2005.

JORDANOVA, Ludmilla. History in Practice. London: Arnold, 2000. 
KANSTEINER, Wulf. Searching for an Audience: The Historical Profession in the Media Age - a Comment on Arthur Marwick and Hayden White. Journal of Contemporary History, v. 31, n. 1, p. 215-219, 1996.

KAZ, Leonel. O que museu tem a ver com educação? O Globo. Rio de Janeiro, 14 jun. 2013. Disponível em: oglobo.globo.com/pais/noblat. Acesso em: 14 jul. 2013

KEAN, Hilda; MARTIN, Paul; MORGAN, Sally (eds). Seeing History: Public History in Britain now. London: Boutle, 2000.

KELLEY, Robert. Public History: its origins, nature and prospects. The Public Historian, v. 1, n. 1, p. 16-28, 1978.

KNIGHT, Oliver. Claude Bowers, Historian. Indiana Magazine of History, v. 52, n. 3, p. 247-268, 1956.

LIDDINGTON, Jill. What Is Public History? Publics and Their Pasts, Meanings and Practices. Oral History, v. 30, n. 1, Women's Narratives of Resistance, p. 83-93, 2002.

; DITCHFIELD, Simon. Public History: A Critical Bibliography. Oral History, v. 33, n. 1, p. 40-45, 2005.

MAIA, Carolina. Eduardo Bueno: como a história se repete no Brasil. Entrevista com Eduardo Bueno. Meus Livros. Veja. 04 set. 2010. Disponível em: http://veja.abril.com.br/blog/meus-livros/entrevista/eduardo-buenolula-repete-paternalismo-de-vargas. Acesso em: 18 abr. 2013.

MAIGUASHCA, Juan. Historians in Spanish South America: Cross-references between Centre and Periphery. In: MACINTYRE, Stuart; MAIGUASHCA, Juan; PÓK, Atilla (eds.). The Oxford History of Historical Writing. Oxford: Oxford University Press, 2011.

MALERBA, Jurandir (org.). A Independência brasileira: novas dimensões. Rio de Janeiro, Editora FGV, 2006.

Lições de história. O Caminho da ciência no longo século XIX. Porto Alegre: EdiPUCRS; Rio de Janeiro: Editora FGV, 2010.

Lições de história. Da história científica à crítica da razão metódica no limiar do século XX. Porto Alegre: EdiPUCRS; Rio de Janeiro: Editora FGV, 2013.

MARSHALL, Francisco. Historiador critica projeto de lei que garante exclusividade para o exercício da profissão. Zero Hora. Porto Alegre, 03 ago. 2013. Disponível em: http://zerohora.clicrbs.com.br/rs/cultura-e-lazer/ segundo-caderno/noticia/2013/08/historiador-critica-projeto-de-leique-garante-exclusividade-para-o-exercicio-da-profissao-4222548.html. Acesso em: 03 ago. 2013. Segundo Caderno.

MESSIAS, Carlos; ALMEIDA, Marcos Rodrigo. Novo livro descontrói mitos sobre América Latina. Folha de São Paulo. São Paulo, 30 ago. 2011. 
Disponível em: http://www1.folha.uol.com.br/ilustrada/967289-novolivro-desconstroi-mitos-da-america-latina.shtml. Acesso em: 10 abr. 2013. Folha Ilustrada.

MOTTA, Rodrigo Patto Sá. Pelo reconhecimento de que a formação acadêmica importa. História Ciências, Saúde. Manguinhos, 2013. Disponível em: http://www.revistahcsm.coc.fiocruz.br/rodrigo-patto-sa-motta-peloreconhecimento-de-que-a-formacao-academica-importa. Acesso em: 27 maio 2014.

NARLOCH, Leandro. Guia politicamente incorreto da história do Brasil. São Paulo: Leya, 2009.

; TEIXEIRA, Duda. Guia politicamente incorreto da História da América Latina. São Paulo: Leya, 2011.

NATIONAL COUNCIL ON PUBLIC HISTORY. A Guide to Graduate Programs in Public History. Indianapolis: IUPUI, 1996.

NUNES, Augusto. Eduardo Bueno, jornalista, tradutor e historiador. Entrevista com Eduardo Bueno. Veja, 20 fev. 2010. Disponível em: http://veja.abril. com.br/blog/augusto-nunes/videos-veja-entrevista/eduardo-buenojornalista-tradutor-e-historiador. Acesso em: 28 mar. 2013.

ODÁLIA, Nilo. Varnhagen e a historiografia brasileira. In: As formas do mesmo. São Paulo: Fundação Editora da Unesp, 1997.

OLIVEIRA, Cecília Helena de Salles. Resenha de 1822 de Laurentino Gomes. Revista de História da Biblioteca Nacional. Ano 6, n. 2, p. 92, nov. de 2010.

PONDÉ, Luiz Felipe. Guia Politicamente incorreto da Filosofia. São Paulo: Leya, 2012.

- Viva o Brasil Capitalista! Folha de São Paulo. São Paulo, 04 jan.

2010. Disponível em: http://www1.folha.uol.com.br/fsp/ilustrad/ fq0401201017.htm. Acesso em: 10 abr. 2013.

Public History, Public Historians, and the American Historical Association. Report of the Task Force on Public History Submitted to the Council of the Association. Dez. 2003. Disponível em: http://www.historians.org/ about-aha-and-membership/aha-history-and-archives/archives/publichistory-public-historians-and-the-american-historical-association. Acesso em: 27 jul. 2014.

RAY, Angela G. The Lyceum and Public Culture in the Nineteenth-Century United States. East Lansing, MI: Michigan State University Press, 2005.

REIS, José Carlos. Anos 1850: Varnhagen; o elogio da colonização portuguesa. In:__. As identidades do Brasil. $2^{a}$ edição. Rio de Janeiro: Editora da FGV, 1999.

RIBEIRO, Andrea; AMOROSO, Mauro. Entrevista com Luciano Raposo de 
Figueiredo Almeida. Revista Mosaico, 06 jul. 2010. Disponível em: http:// cpdoc.fgv.br/mosaico/?q=entrevista/entrevista-com-luciano-raposo-dealmeida-figueiredo. Acesso em: 10 abr. 2013.

RITCHIE, Donald A. When History Goes Public: Recent Experiences in the United States. Oral History, v. 29, n. 1, p. 92-97, 2001.

RODRIGUES, José Honório. Varnhagen: o primeiro mestre da historiografia brasileira. In: História combatente. Rio de Janeiro: Nova Fronteira, 1982.

ROSENZWEIG, Roy. Historians and Audiences: Comment on Tristram Hunt and Geoffrey Timmins. Journal of Social History, v. 39, n. 3, Special Issue on the Future of Social History, p. 859-864, 2006.

. "Not a Simple Task": Professional Historians Meet Popular Historymakers. The Public Historian, v. 22, n. 1, p. 35-38, 2000.

; DAVID, Helen T. The Presence of the Past: Popular Uses of History in American Life. New York: Columbia University Press, 1998.

RÜSEN, Jörn. Razão Histórica. Teoria da História: os fundamentos da ciência histórica. Brasília: UnB, 2001.

. História viva: teorias da história: formas e funções do conhecimento histórico. Traduzido por Estevão de Rezende Martins. Brasília: Editora UnB, 2007a.

- Reconstrução do passado. Teoria da História: os princípios da pesquisa histórica. Brasília: UnB, 2007b.

SAMMUEL, Raphael. Theatres of Memory: vol. I: past and present in contemporary culture. London: Verso, 1994.

SEHLINGER, Peter J.; HAMILTON, Holman. Spokesman for Democracy: Claude G. Bowers, 1878-1958. Indianapolis: Indiana Historical Society, 2000.

THURNER, Mark. The New History and Theory of Latin American History: From Backwater to Cutting Edge. Trabalho apresentado na Inaugural Conference of the International Network for Theory of History. The Future of the Theory and Philosophy of History. Ghent, Bélgica, 10 abr. 2013.

WALLACE, Michael. History Museums in the United States. In: BENSON, Susan; BRIER, Stephen; ROSENZWEIG, Roy (eds.). Presenting the Past: Essays on History and the Public. Philadelphia: Temple University Press, 1986.

WEHLING, Arno. Estado, História, Memória: Varnhagen e a construção da identidade nacional. Rio de Janeiro: Nova Fronteira, 1999.

WEIBLE, Robert. The Blind Man and His Dog: The Public and Its Historians. The Public Historian, v. 28, n. 4, p. 8-17, 2006.

WHITE, Hayden. Meta-História: a imaginação histórica do século XIX. Traduzido 
por José Laurênio de Melo. São Paulo: Edusp, 1992.

WINTER, Jay. Public History and Scholarship. History Workshop Journal, v. 42, p. 169, 1996.

WREDE, Catarina. É Muita História? Revista de História. 17 abr. 2008. Disponível em: http://www.revistadehistoria.com.br/secao/reportagem/ e-muita-historia. Acesso em: 10 mar. 2013.

WRIGHT, Patrick. On Living in an Old Country: the national past in contemporary Britain. London: Verso, 1985

ZBORAY, Ronald J; ZBORAY, Mary Saracino. Literary Dollars and Social Sense: A People's History of the Mass Market Book. New York: Routledge, 2005. 